\title{
The Phenomenon of Using the Word Anjing as a Slang Word for in Daily Communication of Teenagers in Jakarta: A Study of Language and Culture
}

\author{
Gunawan Tambunsaribu \\ \{gunawanreza_tamsar@yahoo.com\} \\ Universitas Kristen Indonesia
}

\begin{abstract}
Teenagers play an important role in the development of slang words. Words that were once considered very harsh when spoken in public were now common among teenagers. This study used a qualitative method with a descriptive approach. The main benefit of the results of this study was to provide knowledge about the development of teenage slang today so that educators and parents can further encourage their children to use language that is good and has positive nuances so that they can create a good language culture in social life. Based on the research findings, the words anjay, anjas, anjir, anjrit, jing/njing, and nying are derived from the root word 'anjing' (dog) which were softened by sound. Based on the results of the analysis, the seven slang words were often used by adolescents to express admiration, surprise, and resentment or anger.
\end{abstract}

Keywords: Slang Words, Anjing, Teenagers, Communication.

Fenomena Penggunaan Kata Anjing sebagai Kata Gaul dalam Komunikasi Remaja di Jakarta: Sebuah Kajian Bahasa dan Budaya

\begin{abstract}
Abstrak. Remaja sangat berperan penting dalam perkembangan istilah-istilah gaul. Katakata yang dahulu dianggap sangat kasar jika diucapkan di tempat umum, sekarang sudah dianggap lazim bagi para remaja. Penelitian ini menggunakan metode kualitatif dengan pendekatan deskriptif. Manfaat utama dari hasil penelitian ini adalah memberikan pengetahuan tentang perkembangan bahasa gaul para remaja saat ini agar para pendidik dan orang tua dapat semakin menggiatkan anak-anaknya menggunakan bahasa yang baik dan bernuansa positif sehingga dapat menciptakan budaya berbahasa yang baik dalam kehidupan bermasyarakat. Berdasarkan temuan penelitian, kata-kata anjay, anjas, anjir, anjrit, jing/njing, dan nying berasal dari kata dasar anjing yang diperhalus bunyinya. Berdasarkan hasil analisis, ketujuh kata gaul tersebut sering digunakan para remaja untuk mengekspresikan rasa kagum, rasa heran atau terkejut, dan rasa kesal atau marah.
\end{abstract}

Kata kunci: Bahasa Gaul, Anjing, Remaja, Komunikasi

\section{Pendahuluan}

Dengan semakin majunya zaman karena pertumbuhan teknologi, ekonomi, dan bidang lainnya semakin berkembang pula bahasa dalam kehidupan sehari-hari manusia. Pergaulan 
para remaja saat ini pun sangat berbeda jika dibandingkan dengan zaman sebelum adanya perangkat elektronik seperti komputer, internet, telepon selular, dan perangkat teknologi lainnya. Pertumbuhan ekonomi juga sangat berpengaruh pada perubahan dan peningkatan bahasa dari zaman ke zaman karena semakin banyak kosakata baru sesuai dengan perangkat teknologi yang ada.

Remaja sangat berperan penting dalam pertumbuhan bahasa-bahasa populer (slang words). Namun ada kata-kata yang dahulu dianggap sangat kasar jika diucapkan di tempat umum sekarang sudah dianggap lazim bagi para remaja sekarang ini. Ketika kata-kata tersebut diucapkan kepada atau dari teman sebaya, kata-kata tersebut tidak lagi bernuansa kasar tetapi malah menjadi kata-kata populer dalam persahabatan mereka. Kata-kata tersebut adalah namanama binatang, nama-nama alat kelamin serta juga kata-kata plesetan dari nama-nama kelamin dan binatang tersebut [1]

Penggunaan kata slang atau sering juga disebut dengan bahasa gaul lebih dominan digunakan oleh para remaja. Kata slang adalah kata-kata yang tidak baku dan biasanya hasil dari plesetan dari sebuah kata baku. Kata-kata gaul tersebut seringkali tidak dipahami para orangtua atau pun para pendidik yang tidak peka dengan perkembangan bahasa gaul dari waktu ke waktu. Pertambahan dan perubahan kata-kata gaul tersebut terjadi seiring dengan perkembangan zaman dan teknologi yang semakin canggih dari masa ke masa.

Bahasa yang baik adalah bahasa yang menggunakan kosa-kata yang mudah dipahami oleh pendengarnya. Seringkali para orangtua bingung dengan bahasa-bahasa gaul para remaja saat ini. Padahal sebagai orangtua semestinya mereka lebih peka dan mencoba mencari makna dari kata-kata gaul yang digunakan oleh para remaja sekarang agar para orangtua memahami baik buruk kosakata tersebut. Banyak kosakata gaul yang kalau kita selidiki adalah plesetan dari kosakata yang bermakna negatif, tabu, dan kasar. Jika budaya berbahasa ini dibiasakan di dunia akademisi, kemungkinan besar akan menciptakan budaya negatif di kalangan masyarakat setelah para siswa dan mahasiswa lulus dan bergabung dengan masyarakat luas.

"Bahasa merupakan bagian dari kebudayaan yang berarti kedudukan bahasa berada pada posisi subordinat di bawah kebudayaan, tetapi sangat berkaitan" [2]. "Budaya (pikiran) akan membentuk bahasa seseorang. Perkembangan bahasa lebih awal satu tahap sebelum berkembangnya pemikiran (budaya) yang kemudian keduanya bertemu sehingga melahirkan pikiran berbahasa dan bahasa berpikir. Kajian bahasa memiliki erat kaitan dengan budaya" [3].

Kriteria yang digunakan untuk melihat penggunaan bahasa yang benar adalah kaidah bahasa. Kaidah itu meliputi aspek tata bunyi (fonologi), tata bahasa (kata dan kalimat), kosakata (termasuk istilah), ejaan, dan makna. Sedangkan, kriteria penggunaan bahasa yang baik adalah ketepatan memilih ragam bahasa yang sesuai dengan kebutuhan komunikasi. Kebutuhan itu bertalian dengan topik yang dibicarakan, tujuan pembicaraan, orang yang diajak berbicara (kalau lisan) atau pembaca (jika tulis), dan tempat pembicaraan [4]. Bahasa adalah produk budaya pemakai bahasa. Para pakar linguistik sepakat bahwa antara bahasa dan budaya mempunyai hubungan yang sangat erat [5].

Ada dua permasalahan yang akan dijawab dalam penelitian ini, yakni 1) Seperti apakah penggunaan bahasa gaul dengan dasar kata 'anjing' dan bentuk plesetan dari kata tersebut dalam komunikasi para remaja saat ini?, dan 2) Dalam situasi seperti apakah para remaja tersebut menggunaan bahasa gaul dengan dasar kata 'anjing' dan bentuk plesetan dari kata tersebut?

Penelitian terdahulu yang membahas mengenai penggunaan kosakata gaul adalah penelitian dari Noni yang berjudul "Kosakata Gaul Remaja di Metro Plaza Mall Kota Pematangsiantar (Kajian Sosiolinguistik)" [7]. Noni secara umum membahas mengenai pola pembentukan, kategorisasi, dan tuturan kosakata gaul yang digunakan remaja di kota 
Pematangsiantar sedangkan penelitian ini meneliti tentang kosakata gaul dalam ruang lingkup yang lebih khusus yaitu hanya pada kosakata gaul plesetan dari kata dasar 'anjing'. Penelitian lainnya yang sudah membahas mengenai penggunaan kosakata gaul adalah hasil penelitian dari Sembiring dan Fasya yang berjudul “Anjing Alay dalam Lagu 'Anjay’: Makiankah?” [8]. Dalam penelitian tersebut, dibahas bentuk lingual, makna bentuk lingual, dan fungsi bentuk lingual dari kata 'anjay', sedangkan penelitian ini secara khusus membahas mengenai jenisjenis kosakata yang timbul dari plesetan kata 'anjing' yang mana kata 'anjay' adalah salah satu dari plesetan dari kata dasar 'anjing' tersebut.

Manfaat utama dari hasil penelitian ini adalah memberikan pengetahuan perkembangan bahasa gaul para remaja saat ini kepada para orangtua khususnya kepada pendidik (guru dan dosen) agar mengetahui serta memahami arti dari kosakata gaul tesebut. Setelah mengetahui dan memahami arti kosakata gaul tersebut, diharapkan agar para orangtua semakin menggiatkan para anak-anaknya menggunakan bahasa yang baik dan bernuansa positif yang secara tidak langsung akan menciptakan budaya berbahasa yang baik dalam kehidupan para remaja sekarang dan yang akan datang.

\section{Metode Penelitian}

Penelitian ini menggunakan metode kualitatif deskriptif. Hasil temuan dalam penelitian dijabarkan dengan menggunakan penjelasan. Sumber data pada sebuah penelitian kualitatif adalah kata-kata dan tindakan, selebihnya adalah data tambahan, seperti dokumen dan lainlain. Dalam penelitian, data yang dipakai adalah berupa tempat, informan, kejadian, dokumen, dan lain sebagainya [9].

Dalam penelitian kualitatif, data penelitian berupa deskripsi kejadian, perilaku, dan interaksi objek penelitian dengan segala konteks yang mengiringinya [10]. Ada dua macam data, yaitu data primer dan data sekunder [11]. Data utama dikumpulkan secara langsung oleh peneliti dari lokasi penelitian (lapangan) saat melakukan pengamatan. Sedangkan data sekunder adalah data yang dikumpulkan oleh peneliti lain yang digunakan oleh peneliti untuk mendukung penelitiannya [12]. Data primer dalam penelitian ini adalah data yang diperoleh langsung dari sumbernya (subjek penelitian), direkam lalu dicatat, yang untuk pertama kalinya dilakukan melalui pengamatan.

Pengambilan data menggunakan purposive sampling. Purposive Sampling adalah teknik untuk menentukan sampel penelitian dengan beberapa pertimbangan tertentu yang bertujuan agar data yang diperoleh nantinya bisa lebih representatif [13]. "Purposive Sampling adalah pengambilan contoh data berdasarkan atas suatu pertimbangan tertentu seperti sifat-sifat populasi ataupun ciri-ciri yang sudah diketahui sebelumnya" [14]. Teknik pengambilan data dengan cara Purposive Sampling ialah mengambil contoh data berdasarkan pertimbangan sehingga berfokus pada tujuan penelitian [15]. Data penelitian diambil dari data rekaman dari tahun 2019 sampai dengan bulan September 2020. Rekaman tersebut diambil tanpa diketahui para partisipan. Peneliti melakukan analisis data dengan menggunakan dengan cara deskriptif yakni dalam bentuk uraian atau kalimat penjelasan. 


\section{Hasil Penelitian dan Diskusi}

Peneliti membahas lima data (frasa/kalimat) dari setiap jenis kata gaul 'anjing' dan plesetannya. Di bawah ini adalah contoh-contoh penggunaan kata dasar 'anjing' dan peesetan dari kata tersebut yang didapatkan oleh peneliti dari hasil rekaman percakapan para remaja saat peneliti melakukan observasi di lapangan.

\subsection{Hasil}

Kata 'anjing' yang diperhalus bunyinya namun tetap berasal dari kata dasar "anjing" diantaranya adalah kata 'anjay', 'anjas', 'anjir', 'anjrit', 'jing/njing', dan 'nying'.

Tabel 1. Datar kosakata gaul dari kata 'anjing' dan pelesetannya.

\begin{tabular}{cll}
\hline No & Jenis kata gaul & Contoh frasa/kalimat dengan kata gaul tersebut \\
\hline 1 & anjing & "Anjing lu. Tasnya bagus banget. Beli dimana lu?" \\
2 & anjas & "Anjas, ada anak baru" \\
3 & anjay & "Anjay. Boleh juga gaya rambut lu Ndro!" \\
4 & anjir & "Anjir, Makin cantik aja lu" \\
5 & anjrit & "Anjrit. Motor lu keren banget. Asu" \\
6 & jing/njing & "Jing. Bau banget \\
7 & nying & "Sana lu Nying. Gangguin gua mulu luh." \\
\hline
\end{tabular}

\subsection{Diskusi}

\subsubsection{Penggunaan kata gaul "Anjing"}

a) "Anjing. Tasnya bagus banget. Beli dimana lu?" Situasi: Melihat teman kantor memakai tas baru.

b) "Anjing. Cepet amat lu larinya" Situasi: Ketika sadar bahwa teman berlari lebih cepat darinya.

c) "Anjing banget. Itu orang nilai IPKnya bagus-bagus". Situasi: menyadari nilai IPK teman rata-rata sangat bagus di semua mata kuliah.

d) "Anjing. Ko bisa begitu?" Situasi: melihat sesuatu yang membuat kagum.

e) "Ditanyain kenapa diam, malah marah. Anjing banget gak sih?" Situasi: Merasa kesal terhadap seseorang yang tidak menghargai niat tulus.

\subsubsection{Penggunaan kata gaul "Anjas"}

a) "Anjas, ada anak baru"

Situasi: Ketika sadar bahwa ada mahasiswa pindahan masuk kelas.

b) "Anjas. Bagus banget gambarannya!" Situasi: Saat melihat hasil karya gambar seorang teman terlihat bagus.

c) "Anjas. Cantik banget lu hari ini" Situasi: Melihat teman dengan dandanan yang sangat anggun dan cantik.

d) "Anjas. Cantik banget cewek lu." Situasi: melihat teman mempunya pacar yang sangat cantik.

e) "Anjas, pinter juga lu ya" Situasi: mengetahui teman yang selama ini dianggap remeh ternyata mempunyai kemampuan lebih daripada dirinya

\subsubsection{Penggunaan kata gaul "Anjay"}

a) "Anjay. Boleh juga gaya rambut $l u$ Ndro!' 
Situasi: Saat melihat teman memiliki gaya rambut baru

b) "Anjay. Ada Melody JKT48"

Situasi: saat dirinya melihat seorang artis yang terkenal.

c) "Anjay. HP lo bagus banget"

Situasi: Melihat teman mempunyai telefon genggam yang bagus.

d) "Anjay. Nilainya bagus juga $l u$ "

Situasi: Saat melihat nilai bagus teman sekolah.

e) "Anjay. Keren banget motor lu"

Situasi: ketika melihat teman punya motor baru.

\subsubsection{Penggunaan kata gaul "Anjir"}

a) "Anjir, Makin cantik aja lu"

Situasi: melihat teman lama di acara reunian.

b) "Anjir. Gede banget IPK lu"

Situasi: ketika tahu bahwa IPK teman tinggi.

c) "Anjir. Macet banget tadi"

Situasi: keluhan tentang keadaan jalan yang macet.

d) "Anjir. Cincin baru tuh. Baru tunangan?"

Situasi: saat melihat teman kantor memakai cincin baru.

e) "Anjir. Mana tahan omongan $l u$ "

Situasi: saat mendengar percakapan teman mengenai prestasinya.

\subsubsection{Penggunaan kata gaul "Anjrit"}

a) "Anjrit. Motor $l u$ keren banget. Asu..."

Situasi: melihat teman punya motor bagus.

b) "Anjrit. Jago banget lu main gamenya"

Situasi: Saat mengetahui kemampuan bagus teman dalam bermain game.

c) "Anjrit. Ko lu bisa menang?"

Situasi: Saat merasa kaget mengetahui teman memenangkan permainan game.

d) "Anjrit. Ada juga yang mau sama $l o$ ".

Situasi: saat kaget mengetahui teman yang wajahnya sederhana punya pacar baru.

e) "Ih. Anjrit. Brengsek. Sakit banget serangan lo"

Situasi: Ketika dalam permainan game, seorang teman mengalahkan permainannya.

\subsubsection{Penggunaan kata gaul "jing/njing"}

a) "Jing. Bau banget!

Situasi: Pada saat teman mencium aroma tidak enak.

b) "Njing, keren banget HP lu kalo buat timpukin anjing"

Situasi: Menggunakan majas metafora untuk merendahkan teman yang memiliki handphone tipe lama.

c) "Njing. IPK $g w$ kalah sama IPK lu. Pinter juga ternyata $l u$ "

Situasi: kaget saat mengetahui teman lebih pinter dalam menyelesaikan tugas sekolah.

d) "Sepatu lu keren banget, jing"

Situasi: Ketika melihat teman mengenakan sepatu baru yang bagus.

e) "Njing. Foto dimane lu? Bagus banget pemandangannya" 
Situasi: Saat melihat foto teman sangat bagus dengan latar pemandangan yang indah.

\subsubsection{Penggunaan kata gaul "nying"}

a) "Monyet juga lu nying. Masa gua yang traktir lu mulu!

Situasi: Pada saat teman agak kesal terhadap temannya yang ingin ditraktir lagi

b) "Sana lu Nying. Gangguin gua mulu luh."

Situasi: Pada saat teman kesal karena temannya bersikap usil

c) "Nying. Masa gua kalah lagi sih"

Situasi: Mengungkapan rasa kesal karena kalah lagi dalam sebuah permainan/game online.

d) "Ko lu ngambil punya gua sih, nying"

Situasi: Ketika melihat seorang teman mengambil miliknya.

e) "Nying. Parah anjing. Lemot banget sih ini komputer"

Situasi: Mengungkapan rasa kesal karena aplikasi yang sedang dipakai prosesnya lamban

\section{Kesimpulan}

Berdasarkan hasil temuan, kata-kata 'anjay', 'anjas', 'anjir', 'anjrit', 'jing/njing', dan 'nying' berasal dari kata dasar "anjing" yang diperhalus bunyinya. Ketujuh kata gaul tersebut sering digunakan para remaja untuk mengekpresikan rasa kagum, rasa heran atau terkejut, dan rasa kesal atau marah. Ekpresi kagum terlihat dari penggunaan kata gaul yang dalam konteks memuji keindahan, prestasi, dan kualitas yang dimiliki orang lain. Ekspresi heran atau kaget terlihat dari penggunaan kata dalam kalimat yang menyatakan adanya sesuatu yang baru terjadi pada seseorang atau suatu benda. Sementara ekspresi marah atau kesal tampak pada kalimat yang konteksnya mengenai perasaan tidak suka terhadap sebuah keadaan yang terjadi kepadanya baik disebabkan oleh sesuatu atau seseorang.

Data penelitian ini secara khusus diambil dari informan dari ruang lingkup terbatas yakni di provinsi DKI Jakarta. Peneliti menyarankan agar peneliti lainnya dapat melakukan penelitian di propinsi lainnya dengan topik yang sama untuk melihat apakah ada kesamaan yang signifikan antara penggunaan jenis kosakata gaul plesetan 'anjing' oleh remaja di kota Jakarta dengan kota-kota lainnya di Indonesia.

\section{Referensi}

[1] Tambunsaribu. The morphological process of slang words used by teenagers in Jakarta and its negative effects in their academic qualifications (A sociolinguistic study."Journal of Applied Studies in Language [Online], 3.2, 202-213, 2019

[2] Koentjananingrat. Bunga Rampai: Kebudayaan, Mentalitas, dan Pembangunan. Jakarta: Gramedia, 1985.

[3] Abdul Chaer. Psikolinguisti: Kajian Teoretik. Jakarta: Rineka Cipta, 2003.

[4] Dendy Sugono. Mahir Berbahasa Indonesia dengan Benar. Jakarta: Gramedia, 2009.

[5] Suryadi. Hubungan Antara Bahasa dan Budaya. Prosiding pada Seminar Nasional Budaya Etnik III, Universitas Sumatera Utara, 25 April 2009.

[6] Abin Syamsuddin Makmum. Karakteristik Perilaku dan Kepribadian pada Masa Remaja, 2003. 
[7] Noni, A. S. Kosakata Gaul Remaja di Metro Plaza Mall Kota Pematangsiantar (Kajian Sosiolinguistik). Universitas Diponegoro, 2018.

[8] Sembiring, S. U., \& Fasya, M. Anjing Alay dalam Lagu 'Anjay': Makiankah?. Konferensi Linguistik Tahunan Atma Jaya, 17, 455-459, 2019.

[9] Arikunto, Suharsimi. Prosedur Penelitian Suatu Pendekatan Praktek. Jakarta: PT. Rineka Cipta, 2002.

[10] Patton, M.Q. Qualitative Evaluation Methods. Beverly Hills: Sage Plublication, 1980.

[11] Faisal, S. Format-format Penelitian Sosial: Dasar-dasar dan Aplikasinya. Jakarta: CV. Rajawali Press, 1989.

[12] Blaxter, L, Hughes C, Thight M. How to Research. Seluk-beluk Melakukan Research. Jakarta: Gramedia, 2006.

[13] Sugiyono. Metode Penelitian Pendidikan Pendekatan Kuantitatif, kualitatif, dan R\&D. Bandung: Alfabeta, 2010.

[14] Notoatmodjo, S. Metodologi Penelitian Kesehatan. Jakarta: Rineka Cipta, 2010.

[15] Arikunto, S. Metode Penelitian Kualitatif. Jakarta: Bumi Aksara, 2006. 